\title{
El planteo lingüístico del Crátilo: alcances y limitaciones
}

\section{The linguistic approach of Cratylus: Scopes and limitations A premissa linguística do Crátilo: alcances e limitações}

\author{
Dra. Tania C. Squizzato ${ }^{1}$
}

Recibido: 27/08/2016 · Aceptado: 25/09/2016

\begin{abstract}
Resumen
El objetivo del presente trabajo es poner de manifiesto las limitaciones y estrechez de miras del planteo lingüístico que se presenta en el diálogo platónico Crátilo. Para ello primero se habrá de mostrar que el verdadero tema (o tema serio) de la obra no es el lenguaje, sino la teoría platónica de las ideas. Una vez conseguido esto, se analizará el contenido estrictamente lingüístico del diálogo, para considerar cuáles son los alcances y limitaciones del planteo platónico. Como resultado de este análisis se observa que en el diálogo no hay tratamiento de la unidad lingüística que es la oración; no hay definición de los términos lingüísticos, ni uso técnico de esa nomenclatura; no hay tratamiento de la verdad como atributo del lenguaje, entre otras conclusiones.
\end{abstract}

Palabras clave: Platón - Crátilo - filosofía del lenguaje - teoría de las ideas

\begin{abstract}
The objective of this work is to highlight the limitations and narrowness of the linguistic approach presented in the Platonic dialogue Cratylus. For this, it first shows that the work's actual theme (or serious theme) is not the language, but the Platonic theory of ideas. Once this is achieved, it analyzes the strictly linguistic content of the dialogue to consider the scope and limitations of the Platonic approach. Findings point out that there is no treatment of the linguistic unit, i.e. the sentence, in the dialogue; there is no definition of linguistic terms, nor technical use of
\end{abstract}

1 Argentina. Especialista en Filología Clásica por Universidad Nacional de Cuyo, Argentina; Doctora en Filosofía por Pontificia Universidad Católica de Valparaíso, Chile. Profesora de lenguas clásicas en la Pontificia Universidad Católica de Valparaíso y en la Universidad Alberto Hurtado. E-mail: taniasquizzato@yahoo.com 
that nomenclature and there is no treatment of truth as an attribute of language, among other conclusions.

Keywords: Plato - Cratylus - philosophy of language - theory of ideas

\section{Resumo:}

O objetivo do presente trabalho é colocar em manifesto as limitações e estreiteza da linguagem que se apresenta no diálogo de Platão de Crátilo. Para fazer isso se deve em primeira instancia mostrar que a verdadeira temática (ou assunto sério) da obra não é a linguajem, mas bem a teoria platônica das ideias. Tendo conseguido isso, vai se analisar o conteúdo estritamente linguístico do diálogo para considerar quais são os alcances e limitações da postura platônica. Com resultado desta análise se observa que no diálogo não existem tratamentos de unidade lingüística que é a oração; não há definição de termos linguísticos, nem uso técnico desta nomenclatura; não há tratamento da verdade como um atributo da linguagem, entre outras conclusões.

Palavras-chave: Platão - Crátilo - filosofia da linguajem - Teoria das ideias.

\section{Introducción}

No existe ninguna obra de las que se nos han conservado de Aristóteles, ni ninguna de Platón -y de Platón, al parecer, se nos han conservado todas-, que tenga por asunto el lenguaje, salvo el Crátilo. Es por ello que este diálogo ha sido considerado como el primer gran antecedente de la filosofía del lenguaje. Ésta, sin embargo, es una afirmación que debe ser matizada. El Crátilo -como todo diálogo platónico- encierra múltiples dificultades, no sólo en relación con el lenguaje, sino también en relación con el origen y el valor de varias de las tesis que en él se discuten. El propósito de estas páginas no es el de esclarecer algunas o las principales oscuridades que manifiesta, ni siquiera pretendemos señalar todos los problemas que este diálogo presenta. Aquí sólo intentaremos mostrar, en primer lugar, la subordinación de la discusión lingüística del Crátilo al tema central de la filosofía de Platón: la teoría de las ideas, y, en segundo lugar, exponer los elementos que el diálogo aporta o no a la discusión lingüística posterior. 
Si bien se ha sostenido ya que en el Crátilo el lenguaje es solo una excusa de Platón para poder exponer la necesidad de las ideas, esta es una afirmación que -hasta donde sabemos- no ha sido demostrada. Por ello, en la primera parte de nuestro trabajo, dividiremos el diálogo en tres secciones para tratar de mostrar que Platón no se toma en serio el problema del lenguaje y que el tema que verdaderamente importa al autor, no es la rectitud de los nombres, sino la necesidad de refutar ciertas tesis de la época y sostener la existencia de una "esencia" de las cosas. Luego, en la segunda parte, analizaremos tres de los planteos lingüísticos del Crátilo (convención y naturaleza de los nombres, nombre y verbo, lenguaje y verdad) para observar cuáles son sus alcances y limitaciones.

Hemos utilizado la edición del texto griego del Crátilo de J. Burnet (Oxford, 1967); todas las traducciones son nuestras.

\section{El tema serio del Crátilo}

Se ha pensado que el Crátilo es un estudio sobre la estructura y el funcionamiento del lenguaje (cfr. Taylor, A. E. Plato, the Man and his Work, London, 1929; en Calvo 345), pero dudamos de que esto sea así por dos razones: primero, porque el tema con que se abre el diálogo no es el lenguaje en general, sino algo mucho más reducido: la rectitud de los nombres; segundo, porque la rectitud de los nombres, planteada por Hermógenes y Crátilo, es un tema que se subordina -casi de inmediato y por completo- al tema que verdaderamente le interesa a Platón: lo que realmente es o lo que es en sí.

El diálogo, entonces, no se ocupa del lenguaje, sino de una pequeñísima porción del lenguaje, el "nombre" (ővo $\mu \alpha$ ), y comienza por analizar nombres propios, lo cual restringe aún más el estudio. Sin embargo, luego se extiende a sustantivos comunes, sustantivos abstractos, menciona algunos adjetivos y verbos. A pesar de esta apertura, no se puede decir que el Crátilo se ocupe de las palabras en general, sino de ciertas palabras. Y las estudia de manera aislada. No trata acerca de la combinación de las palabras en una unidad mayor, como una oración, pero sí menciona el análisis del nombre 
en sus elementos menores, como las sílabas y las letras. Sin embargo, aunque el enfoque es muy reducido, el problema lingüístico del que se ocupa no es menor: la relación o adecuación entre los "nombres" (óvó $\alpha$ ata) y aquello que los nombres nombran, las "co-

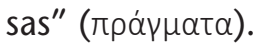

Ahora bien, este problema, el de la adecuación de los nombres, no es el verdadero tema o, mejor dicho, no es el tema de fondo del Crátilo. Creemos, como otros autores, que el problema de la rectitud de los nombres "es una excusa de Platón para sentar su propia epistemología y -en último término- su propia ontología" (Calvo 345$)^{2}$. Como prueba de ello ofrecemos la explicación que a continuación se desarrolla.

El diálogo se abre con la exposición más o menos vaga del problema de la adecuada relación (o rectitud) entre los nombres y aquello que los nombres nombran. Esta adecuación es o bien natural o bien convencional. En el diálogo se pueden reconocer tres partes: $a$. exposición y refutación de la tesis convencionalista de Hermógenes (383a - 391d), b. un largo pasaje con explicaciones etimológicas (391d - 428b), c. exposición y refutación de la tesis naturalista de Crátilo (428b - 440e) ${ }^{3}$. Es posible observar que en la primera y última parte el asunto lingüístico es declinado en favor de un tema ontológico-epistemológico con el cual se consigue la refutación de ambas tesis. En la parte central, que, por lo demás, ocupa la mitad del diálogo completo, el tema lingüístico no es tomado como asunto serio.

2 Cfr. L. Méridier, Platon Cratyle; París, 1969; p. 30: "Le dialogue est avant tout I' esquisse $d^{\prime}$ une théorie de la connasissance: I' étude linguistique qu' il présente, $\mathrm{n}^{\prime}$ en pas que l' enveloppe et le prétexte" (El diálogo es, sobre todo, el esbozo de una teoría del conocimiento: el estudio lingüístico que presenta no es más que un envoltorio y un pretexto). De una opinión semejante es también Gauss, H. Philosophischer Handkommentar zu den Dialogen Platons, Bern, 1956; en: Schmidt Osmanczik LX.

3 Ute Schmidt ha observado que es posible encontrar en el diálogo una tesis convencionalista, expuesta por Hermógenes, y tres tesis naturalistas, de las cuales dos son expuestas por Sócrates (en la parte central) y una última, por Crátilo (Schmidt Osmanczik LXIII y ss). 


\section{a. Tesis convencionalista de Hermógenes y su refutación} (383a - 391d)

La tesis convencionalista que, en principio, sería la más fácil de aceptar, es la primera en ser refutada. Esta refutación se consigue porque se abandona rápidamente el plano lingüístico, para ingresar en el ontológico. ¿De qué modo lo consigue Sócrates? En dos pasos:

Primero, reduce la postura convencionalista a una postura individualista. Hermógenes sostiene -de manera muy vaga, por cierto- que los nombres son correctos por convención:

No puedo persuadirme de que la rectitud del nombre consista en otra que en la convención y el acuerdo. [...] Pues por naturaleza no se ha producido ningún nombre para cosa alguna, sino por uso y costumbre de los que usan y llaman por los nombres. (384c 10-d1, d 6-8)

Hasta aquí la postura es bastante moderada. Sirve para explicar el hecho de que, por una parte, distintos hombres llamen de distinto modo a las mismas cosas -esto lo hacen porque tienen la costumbre de llamarlas así- y, por otra parte, el que los hombres puedan acordar cierta denominación para ciertas cosas. Sin embargo, hay que reconocer que la tesis así expresada necesita ciertos ajustes. Entonces Sócrates avanza del siguiente modo:

Probablemente dices algo razonable, Hermógenes, pero veámoslo con cuidado. ¿Dices que el nombre de cada cosa es aquél que alguien podría asignarle?

Hermógenes: A mí, al menos, me lo parece. [...]

Soc.: ¿Acaso cada cosa tiene el nombre aquél que cada uno podría decir que tiene?

Her.: Sí.

Soc.: ¿Acaso también cuantos nombres podría decir uno que tienen las cosas, tantos tendrán y cada vez que lo diga? 
Her.: Yo, al menos, Sócrates, no tengo otra rectitud del nombre que esa: es posible que yo dé a cada cosa un nombre que yo acostumbre usar, y tú le des otro, que tú acostumbras usar. (385a 1-3, 385d 2-9)

Afirmar que los nombres son convencionales no significa necesariamente afirmar que cada uno pueda dar a cada cosa el nombre que se le antoje. Pero Sócrates necesita que su interlocutor llegue a esa afirmación, porque su interés está puesto en refutar la tesis de Protágoras.

Soc.: Adelante, pues, Hermógenes, veamos si también te parece que las cosas son así: que su esencia [oúoía] es para cada uno de manera particular, como decía Protágoras al afirmar que el hombre es "la medida de todas las cosas" -por consiguiente, como cuales me parecen que sean las cosas, tales son para mí y cuales te parezcan a ti, tales serán para ti- ¿o te parece que ellas tienen cierta estabilidad de su esencia? (385e 4-386a 4)

Aquí pues pasa al plano que verdaderamente importa: la esencia (oúoía) de las cosas. Con ello Sócrates no sólo apunta a refutar la tesis de Protágoras, sino también la de Eutidemo, tesis que en el Crátilo se enuncia así: "todo está en todo de igual manera, al mismo tiempo y

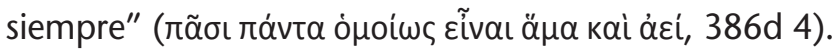

Así, pues, se puede observar que lo que hay que discutir, antes que la rectitud de los nombres, es la posibilidad misma del conocimiento. Pues tanto la tesis de Protágoras como la de Eutidemo niegan esta posibilidad. Bien porque las cosas no tienen ningún atributo, sino aquellos que le asigne cada individuo (Protágoras); bien porque las cosas acepten todos los atributos (incluso contradictorios), del mismo modo, al mismo tiempo y siempre (Eutidemo). Llevada la discusión a este punto, Sócrates afirma la necesidad de que exista una esencia (oủoía) estable ( $\beta \dot{\varepsilon} \beta a \iota$ เo) para todas las cosas y que

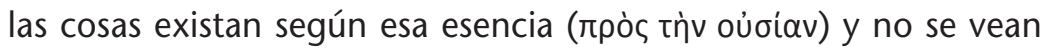

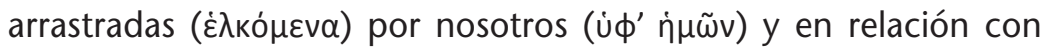

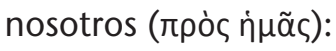


Entonces si todas las cosas no son para todos de manera semejante, al mismo tiempo y siempre, si cada una no es para cada uno de manera particular, entonces es evidente que las cosas son ellas mismas porque tienen cierta esencia propia y estable y no son arrastradas en relación con nosotros ni por nosotros para arriba o para abajo en nuestra imaginación, sino que existen por sí mismas y según la esencia que les es propia, por la que son por naturaleza. (386d 8-e 4).

Después de dejar sentado esto, Sócrates introduce una definición que primero servirá para refutar la tesis convencionalista, pero que después -al ser refutada la tesis naturalista- tendrá que ser negada ella también: "el nombre es un instrumento útil para enseñar y distinguir

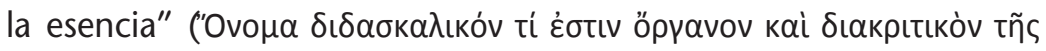
oủoías, 388b 13-c 1). Si esto es así, entonces, puesto que no cualquiera puede distinguir la esencia de las cosas, no cualquiera debe dar el nombre a las cosas.

El ataque, entonces, no es contra la tesis convencionalista del lenguaje, sino contra la doctrina del homo mensura de Protágoras.

\section{b. Largo pasaje epistemológico (391d - 428b)}

Una vez refutada la tesis convencionalista, tiene lugar la parte más extensa del diálogo, donde se ofrece un centenar de etimologías, la mayoría de las cuales son falsas (Calvo 353). Se analizan etimológicamente sustantivos propios (nombre de héroes y de dioses), sustantivos comunes genéricos, sustantivos comunes que indican fenómenos naturales, sustantivos abstractos, sustantivos comunes concretos, adjetivos, verbos y participios. Sin embargo, a cada momento se hace patente que el procedimiento es poco serio.

Así, por ejemplo, no bien Sócrates empieza a dar la etimología de los nombres de los dioses, nota la facilidad con que puede realizar tal tarea, pues si recordara cierta genealogía de los dioses, "no pararía

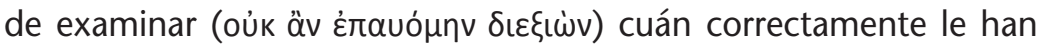


sido dados los nombres" (396c 5-6) y hace esto con una supuesta sabiduría (бoфía), que le ha caído "no sé de dónde" (396d 1). A lo que Hermógenes, su interlocutor, responde: "Por cierto, Sócrates, también a mí me parece de buena fe que de repente estás dando oráculos como los entusiasmados" (396d 2-3).

Unas páginas después, tras esbozar una teoría del lenguaje como mímesis, Sócrates vuelve a insistir sobre la esencia de las cosas:

Soc.: Pero ¿qué es esto entonces? ¿No te parece que hay una esencia para cada cosa, como el color y las cosas que decíamos hace poco? En primer lugar, el color mismo y el sonido, ¿no tienen cada uno de ellos cierta esencia y lo mismo todas las otras cosas que son dignas de esta denominación del ser?

Her.: Me parece al menos a mí.

Soc.: ¿Y qué? Si alguien pudiera imitar para cada cosa esto mismo, es decir, la esencia, mediante letras y sílabas, ¿acaso no mostraría lo que cada cosa es? ¿O no?

Her.: Ciertamente, lo haría. (423e 1-424a 1)

Sin embargo, luego de avanzar en el análisis de unas cuantas palabras, observa lo ridículo que es todo ello: "Creo, por cierto, que es evidentemente ridículo [ $\left.ү \varepsilon \lambda \circ \lambda_{\alpha}\right]$, Hermógenes, que las cosas se hagan patentes al ser imitadas mediante letras y sílabas" (425d 1-3).

Una vez analizadas etimológicamente un centenar de palabras, Sócrates observa que sólo se ha ocupado de palabras secundarias, es decir, palabras compuestas a partir de otras que serían las primeras o "nombres primitivos" ( $\pi \rho \tilde{\tau} \tau \alpha$ óvó $\mu \alpha \tau \alpha, 425 d$ ). En consecuencia, se ve en la obligación de explicar estas primeras palabras o nombres primitivos. Sin embargo, Sócrates desconfía de una doctrina sobre los nombres primitivos mismos: "realmente las cosas que he visto en relación con los nombres primitivos me parece que son muy extrava-

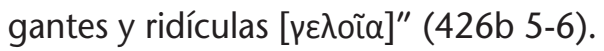

Al final de la exposición de las etimologías confiesa: "Por cierto, Crátilo, ni yo mismo podría sostener nada de lo que he dicho y pasaba revista 
[a estas cosas] con Hermógenes como me ha ido pareciendo" (428a 6-8). Crátilo, admirado, también piensa que Sócrates ha estado dando oráculos, poseído por una Musa. Entonces Sócrates replica: "mi buen Crátilo, también yo hace tiempo que me vengo admirando de esta

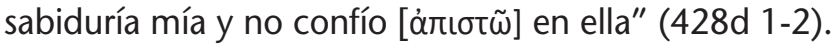

Aunque algunos autores han querido salvar la seriedad de este pasaje $\mathrm{e}^{4}$ hay, sin embargo, demasiados indicios para pensar que Sócrates no hace más que burlarse de quienes creían que era fundamental recurrir al análisis etimológico de los nombres para acceder al conocimiento de las cosas 5 . El pasaje de las etimologías, que ocupa más de la mitad del diálogo, donde se descomponen más de cien palabras para explicar su significado, difícilmente pueda tomarse en serio; "lingüísticamente hablando, esta sección no tiene valor alguno" (Calvo 353).

\section{c. Tesis naturalista de Crátilo y su refutación (428b - 440e)}

Así como en la primera parte, a propósito de la tesis convencionalista de Hermógenes, Sócrates desvía la atención hacia las doctrinas de Protágoras y Eutidemo, así también, en el marco de la refutación de la tesis naturalista de Crátilo, deriva la conversación hacia la doctrina del movimiento universal de Heráclito, que Crátilo profesa:

Sóc.: Otra vez, pues, investiguemos las cosas que antes consideramos en detalle. Si todo se mueve, cambia y fluye, de qué modo diremos que los nombres nos señalan la esencia [oủoía]. ¿Es de otro modo o así te parece que la muestran?

\footnotetext{
4 Cfr. Sedley, D. "The etimologies in Plato's Cratylus", JHS 118, (1998) pp. 140154, en Casadesús Bordoy 54. Cfr. además Grote, G. Plato and other Companions of Socrates, London, 1865; Ross, D., "The date of Plato's Cratylus". Rev. Intern. Philos. 9 (1955); Dervolav, J. Platons Sprachphilosophie im "Krathylos" und in den späteren Schriften, Darmstadt, 1972; en Calvo 353.

5 Sobre los destinatarios de las burlas de Sócrates en el pasaje de las etimologías, ver las interpretaciones basadas en los últimos descubrimientos arqueológicos (Casadesús Bordoy 53-71).
} 
Crát.: Muy bien, y la señalan con corrección. (436e 2-437a 1).

Luego de mostrar que los nombres no enseñan la esencia de las cosas, el diálogo termina con la objeción a la tesis de Heráclito. Porque, así como las doctrinas de Protágoras y Eutidemo deben ser desestimadas por no hacer posible el conocimiento, algo semejante ocurre con la doctrina heraclítea. Platón vuelve entonces a plantear la necesidad

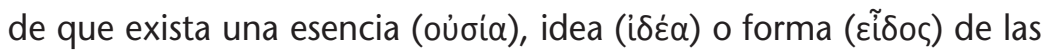
cosas, para que sea posible conocerlas. $Y$ esa esencia, idea o forma es algo que no cambia. Pues,

i. Si todo cambia, no sería posible hablar de algo, pues llegaría a ser otra cosa mientras hablamos de eso:

¿Acaso es posible decir con rectitud primero que [lo bello] existe y después que es de tal índole, si siempre se nos escapa? ¿O será necesario que, no bien nosotros hablamos de él, al punto se convierte en otra cosa y se nos escapa y ya no es más del mismo modo? (439d 8-11).

ii. Pero, ¿cómo podría existir algo que nunca es de la misma manera? Es decir, ¿cómo podría "ser" algo que es y deja de ser?:

¿Cómo podría ser algo aquello que nunca es del mismo modo? Pues si se mantiene del mismo entonces, en ese momento es evidente que no cambia nada. Y si siempre es del mismo modo y es lo mismo, ¿cómo podría cambiar o moverse esto, lo que en nada abandona su propia forma? (439e 1-5).

iii. Si todo cambia, no es posible el conocimiento. Pues cuando alguien intentara conocer algo, eso se volvería otra cosa diferente, y no sería posible saber qué es:

Pero entonces no podría ser conocido por ninguno. Pues al mismo tiempo que uno se acerca para conocerlo, se vuelve otro y algo diferente, de modo tal que ya no se podría conocer qué o cómo es. (439e 7-440a 2). 
iv. Luego, o bien se admite que existe algo en sí y lo mismo en relación con cada uno de los entes, que es siempre así como es, o bien se renuncia al conocimiento ${ }^{6}$.

Así, pues, el diálogo, que comienza planteando cuestiones lingüísticas, termina planteando cuestiones epistemológicas.

El asunto que le importa a Platón no son los nombres (óvó $\mu \alpha t \alpha)$, sino las cosas (ővta), o más precisamente, la esencia de las cosas (oủ oía

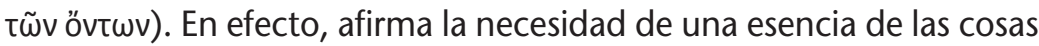
en los tres momentos del diálogo. En la primera parte, para refutar las tesis de Protágoras y Eutidemo (385e - 386a); en la segunda parte, para mostrar que, si los nombres manifiestan las cosas, entonces deben manifestar su esencia (423e - 424a), y en la tercera parte, para refutar la tesis de Heráclito (439 e - 440 d). Si las cosas no tienen una esencia estable, no es posible su conocimiento. El asunto del Crátilo no es, entonces, un asunto lingüístico, sino más bien un tema ontológico y epistemológico.

\section{Los temas lingüísticos del Crátilo}

Aunque pueda afirmarse que, en el Crátilo, el interés de Platón está puesto más en asuntos de orden ontológico y epistemológico que en el lenguaje mismo, no puede negarse que en él irrumpen asuntos lingüísticos de relativa importancia. Entre ellos hay por lo menos tres, que se repetirán, de algún modo, en los posteriores planteos lingüísticos de Aristóteles. Entre estos temas están: $a$. el carácter convencional del lenguaje, $b$. la identificación de los elementos que componen una oración, y c. el problema del lenguaje como portador de verdad y falsedad. Expondremos cada uno de ellos, tal como son abordados en el Crátilo, para ver los alcances y limitaciones que presentan. 


\section{a. Convención y naturaleza}

El primer tema que el Crátilo aporta a la discusión lingüística es, pues, la relación que guarda el nombre con aquello que el nombre nombra. Esta relación se presenta en dos posibilidades: o bien se trata de una relación convencional, o bien se trata de una relación natural.

La rectitud de los nombres, rectitud entendida como la adecuación o no adecuación entre el nombre y la cosa, se plantea entonces bajo una antinomia característica de la discusión sofística: naturaleza y

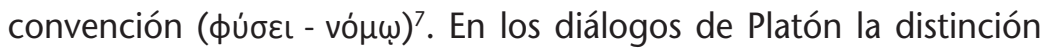

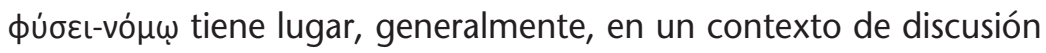
ético-política. Así, por ejemplo, en Gorgias 482e - 484c, Calicles le espeta a Sócrates el no reconocer abiertamente que lo justo y lo injusto pueden ser considerados según su naturaleza o según la convención ${ }^{8}$. En Protágoras, Hipias comienza su parlamento distinguiendo a sus interlocutores como parientes, familiares y ciudadanos por naturaleza y no por convención 9 . En Menexeno 245d se habla de aquellos habitantes de Atenas que son extranjeros por naturaleza, pero griegos por ley.

En el Crátilo la oposición, útil para hacer diferenciaciones en cuestiones ético-políticas, es llevada al plano lingüístico. Ambas consideraciones, sin embargo, son atacadas: ni los nombres son correctos por naturaleza, ni son correctos por convención. La tesis convencionalista, que, en principio, es la más fácil de aceptar, es la primera en ser refutada. Para hacerlo Sócrates necesita trasponerla a la doctrina del homo mensura de Protágoras (como vimos en el apartado anterior). Sin embargo, como el ataque no es contra la tesis convencionalista propiamente

\footnotetext{
Aristóteles observó que esta oposición era el lugar más extendido ( $\pi \lambda \varepsilon$ ז̃otoৎ тónoৎ) para conducir a paradojas y que todos los antiguos creían que correspondía argumentar según naturaleza o convención (cfr. Sophistici Elenchi 173a 7-10).

$8 \quad$ En este pasaje la consideración, según naturaleza y convención, se extiende a

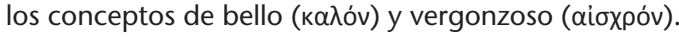

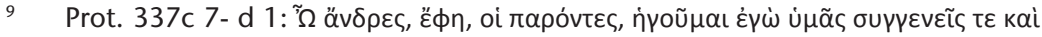

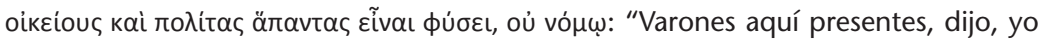
creo que todos vosotros sois parientes, familiares y ciudadanos por naturaleza, no por convención".
} 
tal, la tesis que postula, en última instancia, que las cosas tienen el nombre que los usuarios les den, no sufre mayores inconvenientes.

Una vez refutada la tesis convencionalista de Hermógenes que, de haber sido planteada y defendida de mejor manera, habría resultado la más plausible, se asume momentáneamente la validez de la tesis naturalista:

Soc.: Entonces es posible, Hermógenes, que no sea trivial, como tú crees, la designación de los nombres, ni de hombres triviales ni de cualquiera. Y Crátilo dice la verdad, al decir que las cosas tienen sus nombres por naturaleza, y que no cualquiera es un forjador de palabras, sino solo aquel que ponga atención en el nombre que cada cosa tiene por naturaleza y que pueda aplicar la forma de las cosas a las letras y sílabas. (390d 7-e 4)

A partir de aquí Platón comienza a proporcionar los fundamentos de la tesis naturalista. Esta fundamentación ocupa mucho más espacio que la exposición y refutación del convencionalismo, y es llevada a cabo por el propio Sócrates y no por Crátilo, como se podría haber esperado ${ }^{10}$. La teoría naturalista, según la cual cada cosa tiene un nombre que le corresponde por naturaleza, resulta, para el lector moderno, contra-intuitiva. Sin embargo, en el momento en que se compuso este diálogo no era una cuestión baladí, ni lo fue después en el período helenístico (cfr. Mársico 39). Si Platón se toma tanto trabajo en exponerla y refutarla es porque seguramente la tesis tenía la fuerza y la vigencia suficientes como para preocuparlo ${ }^{11}$.

10 Schmidt O. (LXIII) afirma que hay tres tesis convencionalistas, dos son de Platón y una de Crátilo. Mársico (40) sostiene que, en realidad, la conversación con Crátilo, que tiene lugar en la tercera y última parte del diálogo, se asienta en una construcción previa, realizada en la segunda parte por el propio Sócrates a manera de "regalo griego" para Crátilo.

11 Es muy probable que, en este diálogo, Platón se haya enfrentado a su condiscípulo Antístenes (cfr. Mársico 28-40). 
Ahora bien, la cuestión acerca de si las palabras significan algo por naturaleza o por convención no es tratada en ningún otro diálogo de Platón y es completamente ajena a la especulación aristotélica sobre el lenguaje ${ }^{12}$.

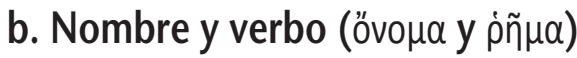

Por otra parte, es en el Crátilo donde se esboza por primera vez la

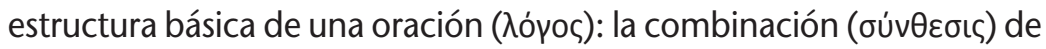

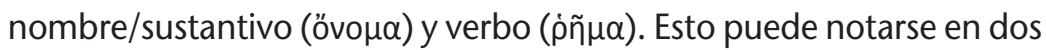
pasajes: "a partir de sustantivos y verbos haremos con su combinación

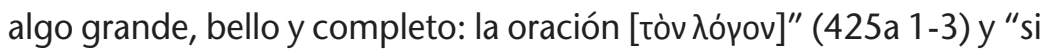
es posible disponer de este modo verbos y sustantivos, también necesariamente [será posible disponer] oraciones: pues las oraciones son, en cierto modo, como yo creo, la combinación de ellos" (431b 5-c1).

Es posible que en este diálogo Platón use por primera vez la palabra jñua para significar la categoría gramatical 'verbo'. En 426e 1-3, enumera una serie de infinitivos de significación similar ${ }^{13}$. Sin embargo, en el Crátilo el uso de la palabra piñua es bastante flexible. Salvo en los tres lugares mencionados (425a 1-3, 426e 1-3, 431 b 5-c1), en el resto de sus apariciones significa 'locución', 'expresión', como se pone de manifiesto en 399 b1, 6, 421 b 3, e 1-2.

Es importante observar que en el Crátilo apenas si se dice que la ora-

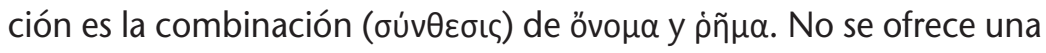
definición de oración, no es suficiente con decir que ella surge de la combinación de sustantivos y verbos (pues la mera yuxtaposición de

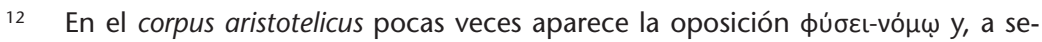
mejanza de lo que ocurre en Platón, la mayoría de las referencias se restringen a las obras de tema ético-político. Aristóteles no se pregunta nunca por la posibilidad de que los nombres puedan significar algo por naturaleza. Asume, sin cuestionar, que las palabras y oraciones significan por convención, como queda de manifiesto en De interpretatione 1, 2, 3 y 4 .

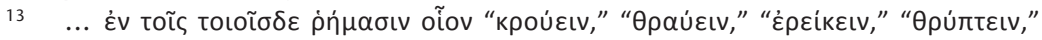

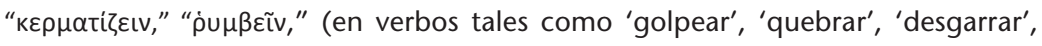
'quebrantar', 'cortar', 'voltear').
} 
övoua y j̃̃n $\mu$ no constituye, ipso facto, una oración, como después se explicará en el Sofista 262a-c). Tampoco se da ninguna definición

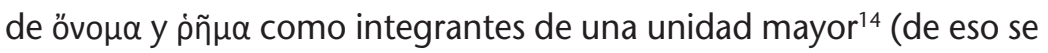
ocupará Platón también en el Sofista).

\section{c. La verdad/falsedad de las palabras y la verdad/falsedad de la proposición}

Uno de los temas más importantes del Crátilo es la relación del lenguaje con la verdad y la falsedad. Este problema es planteado dentro del marco de una discusión propia de la época de Platón y que, de alguna manera, se vincula con la doctrina de Parménides. En efecto, la tesis parmenídea "no es posible decir lo que no es"15 derivó, en tiempos de la sofística, en la aserción de que es "imposible hablar falsamente". Aunque no es este el lugar donde explicar de qué manera se produjo esta derivación, preciso es indicar que esta última tesis es un asunto que le preocupó sobremanera a Platón. Arremete contra ella dos veces en el Crátilo, primero al dialogar Sócrates con Hermógenes, en 385b y ss, después al hacerlo con Crátilo, en $429 d$ y ss ${ }^{16}$. En la segunda aparición del problema, la tesis queda completamente expuesta:

14 Sí se da, en algún sentido, una definición de ővoua. En 388a 8 - b 10, Platón pregunta si el nombre no es un instrumento (öpyavov) para enseñarse las cosas

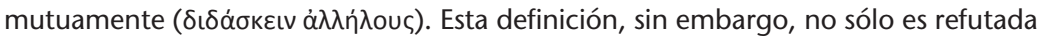
en esta misma obra, sino que además está muy lejos de la que ofrecerá después en Sofista 262a.

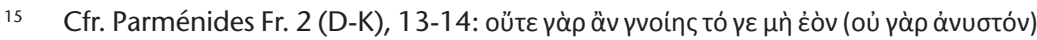

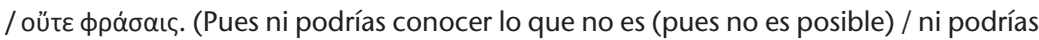

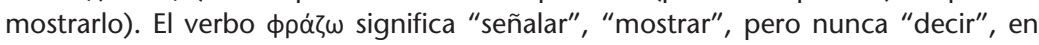
Homero (Cfr. Liddell-Scott sub voce фpáł $\omega$ ). La acepción de "decir" aparece recién con Píndaro. Parménides es contemporáneo de Píndaro, pero si es verdad que imitaba el estilo épico, no debió haber utilizado este verbo con la acepción de "decir".

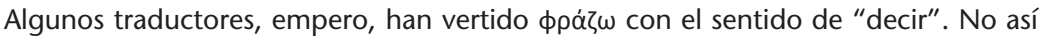
A. Gómez-Lobo, cuya versión española y comentario nos parece lo mejor que, sobre el poema de Parménides, se ha escrito en nuestra lengua.

16 Platón insiste reiteradamente sobre este tema (cfr. Eutidemo $286 \mathrm{~b}$ y ss, Sofista 251 a y ss; Teeteto $187 \mathrm{~d}$ y ss). 
Sóc.: ¿Acaso [dices] que es absolutamente imposible decir algo falso, acaso no significa eso tu razonamiento? Pues son muchos los que lo dicen, querido Crátilo, no sólo ahora sino también antes.

Crát.: Pues ¿de qué manera, Sócrates, alguien al decir lo que dice, podría decir lo que no es? ¿Acaso no es esto decir algo falso: decir lo que no es? (429d 1-5)

Entre los que, en tiempos de Platón (vũv), pueden haber sostenido una tesis semejante, se ha creído reconocer a Antístenes (cfr. Calvo 351 y Mársico 39ss). La referencia a los de antes ( $\pi \alpha \dot{\lambda} \alpha \iota)$ debe ser, probablemente, a los representantes de la escuela eleática. En la respuesta de Crátilo se ve claramente la vinculación con la tesis de Parménides (Fr 2 D-K).

No es este el lugar para comentar las consecuencias de esta concepción, ni la salida que encontró Platón para superarla. Sin embargo, es en el primer ataque que tiene lugar en el Crátilo contra esta tesis, donde Sócrates incurre en un paralogismo que nos interesa señalar.

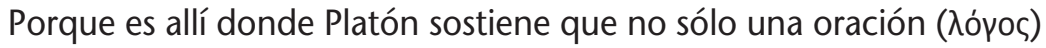
puede ser falsa, sino también sus partes.

Soc.: ¿Llamas a algo "decir verdad" y "decir falsedad"? [...] ¿No habría entonces una oración verdadera y otra falsa? [...] ¿Acaso la que dice como son las cosas, sería la verdadera? ¿Y la que dice como no son, la falsa? [...] ¿Es posible, acaso, esto: decir en una oración lo que es y lo que no es? La oración verdadera, ¿es verdadera por completo, pero sus partes no son verdaderas? / No, sino que también sus partes [son verdaderas].

Her: No, sino también sus partes.

Soc: ¿Acaso son verdaderas las partes grandes, pero las pequeñas no? ¿O todas lo son?

Her: Todas [...].

Soc: ¿Es posible entonces que digas que la parte más pequeña de la oración no es otra que el nombre? [...] ¿Acaso 
se dice también éste [el nombre] de la oración verdadera? [...] Es verdadero, como dice. ¿Y no es falsa la parte de [la oración] falsa? [...] Entonces ¿es posible decir un nombre falso y otro verdadero, como también la oración? (385b 2-d 1) $)^{17}$.

La tesis de que las palabras pueden ser verdaderas o falsas, enunciada en el Crátilo, no vuelve a aparecer en Platón (y es negada por completo en el capítulo primero del tratado aristotélico Acerca de la interpretación).

\section{Conclusión: Limitaciones del planteo lingüístico del Crátilo}

Aunque pueda afirmarse que Crátilo es el primer gran estudio lingüístico en la historia de la filosofía, también hay que reconocer, como se ha tratado de mostrar en las páginas anteriores, que su planteo sobre el lenguaje es muy limitado. Sobre las deficiencias del programa lingüístico del Crátilo se puede decir lo siguiente:

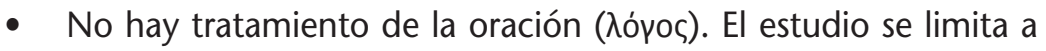
una parte de ella, los nombres (óvó $\mu \alpha \tau \alpha$ ), pero los nombres no son tratados como partes de la oración, salvo ciertas excepciones. Entre las pocas veces en que el nombre es tratado como parte de la oración, hay una en que se incurre en un paralogismo (385c, en el controvertido pasaje donde se plantea que las partes de la oración falsa han de ser también ellas falsas).

- No hay definición de las partes elementales de la oración, esto es, no hay definición del sustantivo (ővo $\mu \alpha$ ), ni del verbo (j̃̃n $\mu$ ). Por

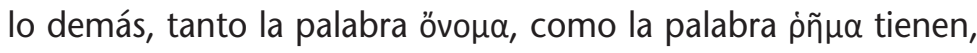
en el diálogo, un uso bastante ambiguo. Pues, por una parte, övoua significa generalmente 'nombre propio', pero en algunos lugares puede tomar el valor de 'sustantivo' (como en 425a) o 
'palabra', como cuando, en el análisis etimológico, el término övoua se extiende a adjetivos (417a, d, etc.) y a verbos (414b). Por su parte, ’ंñ $\mu \alpha$ puede significar 'verbo' (como en 425a y $431 b-c$ ) o 'locución' (como en 399b, 421b y c), entre otras cosas.

- No hay clasificación ni tratamiento de las categorías gramaticales en general, sino principalmente de los sustantivos propios. Aunque se menciona algunos adjetivos y verbos, no se indica qué diferencia hay entre estas categorías gramaticales.

- No hay tratamiento de la verdad y falsedad como atributo del lenguaje y del pensamiento. El problema de la verdad y la falsedad se restringe al tópico de la época, según el cual no es posible decir algo falso.

- No se evidencian las tres esferas, que tendrán su importancia en la especulación posterior: expresión lingüística - pensamiento cosa (cfr. Aristóteles, De interpretatione 1), salvo tal vez cuando se sostiene que hay una "forma del nombre que corresponde a cada

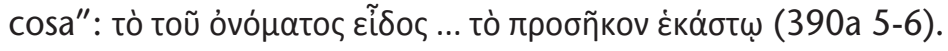

Independientemente del valor que algunos estudiosos puedan asignar a alguna de las tesis sostenidas en el Crátilo, la desconfianza que el lenguaje le genera a Platón, cosa que -esperamos- haya quedado manifiesta en este capítulo, es lo suficientemente importante como para justificar la escasez de aportes del Crátilo.

\section{Bibliografía}

\section{Fuente:}

Burnet, J. Platonis Opera. Recognovit brevique adnotatione critica instruxit I. Burnet. Oxford: Oxford University Press, 1967. 7 Vols.

Diels, H. und Kranz, W. Die Fragmente der Vorsokratiker, vol. 1. Berlin: Weidmann, 1951. Vol 1.

Minio-Paluello, L. Aristotelis Categoriae et Liber De interpretatione. Recognovit brevique adnotatione critica instruxit L. Minio-Paluello. Oxford: University Press, 1966. 
Ross, W. D. Aristotelis Topica et Sophistici elenchi ed. W.D. Ross. Oxford: Clarendon Press, 1958.

Instrumenta:

Astius, D. F. Lexicon Platonicum sive vocum Platonicarum. Berlin: Hermann Barsdorf, 1908. 2 vols.

Liddell - Scott - Jones. A Greek-English Lexicon. Oxford: University Press, 1989.

\section{Secundaria:}

Calvo, J. L. "Introducción" a Crátilo. Platón, Diálogos II. Barcelona: RBA, 2007 (Madrid: Gredos, 1982), 337-355.

Casadesús Bordoy, F. "Nueva interpretación del Crátilo platónico a partir de las aportaciones del Papiro de Derveni", Emérita, Revista de Lingüistica y Filología Clásica LXVIII 1(2000): 53-71.

Gómez-Lobo, A. El poema de Parménides. Texto griego, traducción y comentario de A. Gómez-Lobo. Santiago de Chile: Editorial Universitaria, 2000.

Mársico, C. "Introducción". Platón, Crátilo. Buenos Aires: Losada, 2006. 7-80.

Méridier, L. Platon Cratyle ed. L. Méridier, Platon Oeuvres Complètes Tome V Partie 2. Paris: Les Belles Lettres, 1969.

Schmidt Osmanczik, U. "Introducción" a Platón, Cratilo. México: UNAM, 1988. I-CXXXVIII. 